\title{
A Review of Exogenous Factors Implicated in the Induction of Cutaneous Melanoma
}

\author{
Jacob M. Hands ${ }^{1}$, Lawrence S. Moy²
}

${ }^{1}$ University of California, Berkeley, CA

${ }^{2}$ Advanced Aesthetics \& Cosmetic Dermatology, University of California, Los Angeles, CA

\section{ABSTRACT}

Melanoma is an increasingly pervasive form of malignant skin cancer. Cases of cutaneous melanoma are on the rise across ages and global populations, with incidence increasing significantly for both men and women. Accordingly, the identification of modifiable behaviors is of paramount concern. Previous reviews have focused on specific risk factors (e.g. UVR, pollution, diet, hormonal supplementation) to the near exclusion of other contributory factors. This review strives to report an inclusive range of exogenous variables linked to cutaneous melanoma incidence. In this review, we examine the various contributions of exogenous factors linked to the induction of cutaneous melanoma. Factors for consideration include but are not limited to: long-wave Ultraviolet A (UVA), short-wave Ultraviolet B (UVB), hormonal supplementation, diet, smoking, alcohol, vitamin supplementation, ionizing radiation, pollution, and chemical exposure.

\section{INTRODUCTION}

Melanoma is an increasingly pervasive form of malignant skin cancer. Cases of cutaneous melanoma are on the rise across ages and global populations, with incidence increasing $1.6 \%$ and $1.5 \%$ per annum for men and women respectively - the single largest increase in "common cancers" among men, and the next leading malignancy among women. ${ }^{1}$ Accordingly, the identification of modifiable behaviors is of paramount concern. Previous reviews have focused on specific risk factors (e.g.
UVR, pollution, diet, hormonal supplementation) to the near exclusion of other contributory factors. This review strives to report an inclusive range of exogenous variables linked to cutaneous melanoma incidence. In this review, we examine the various contributions of exogenous factors linked to the induction of cutaneous melanoma. Factors for consideration include but are not limited to: long-wave Ultraviolet $A$ (UVA), short-wave Ultraviolet B (UVB), hormonal supplementation, diet, smoking, alcohol, vitamin supplementation, ionizing radiation, pollution and chemical exposure. 


\section{UVA \& UVB}

$$
\begin{aligned}
& \text { UVA (>315-400 nm) } \\
& \text { UVB (>280 to } 315 \mathrm{~nm}) \\
& \text { UVC }(200-280 \mathrm{~nm})
\end{aligned}
$$

\section{Scope \& Frame}

Broadly, ultraviolet radiation (UVR) can be defined as wavelengths nested between those of the visible and the $x$-ray on the spectrum of electromagnetic radiation. UVR can be segmented into three distinct subtypes: Ultraviolet $A$, Ultraviolet $B$, and Ultraviolet-C. As each wavelength passes through our atmosphere, it is absorbed to varying degrees by extent ozone. While ozone is near impenetrable to UVC and, to a lesser extent UVB, it is notably porous with respect to UVA. ${ }^{2}$ As such, our analysis will focus on UVR subtypes that are likely to be encountered and, hence, contributory. Thus, what we refer to as UVR will denote the mutual contribution of UVA \& UVB.

UVR has long been implicated in melanomagenesis. ${ }^{3,4}$ It has been estimated that UVR exposure alone can account for $\sim 60-70 \%$ of all cases of cutaneous melanoma. ${ }^{5}$ UVR exposure is considered the predominant exogenous driver of all cutaneous melanoma cases. ${ }^{6}$ However, the role of UVR in the induction of cutaneous melanoma is less apparent.

UVR's role in the pathogenesis of cutaneous melanoma pervades academic journals. These views have evolved over the course of decades. Research spanning the early 1970 s to late 1980s would attribute cutaneous melanoma cases to periods of intense exposure to UVB radiation. ${ }^{7}$ Similarly, UVA was considered an insufficient means of induction because it was unable to directly alter DNA and generate mutagenic species thought necessary to the pathogenesis of cutaneous melanoma. ${ }^{8}$ Discussion in the following decades (1990s-present) would both confirm and reject previous hypotheses regarding the role of UVR in melanomagenesis. ${ }^{9-11}$ Though UVB was confirmed as a possible exogenous driver of cutaneous melanoma, UVA emerged as an additional exogenous factor for consideration.

\section{UVB}

UVB's role in melanomagenesis is seldom disputed. Though UVB is estimated to account for less than $5 \%$ of all solar radiation, it's role in the induction of cutaneous melanoma is pronounced. UVB has been shown to induce DNA lesions directly via cyclobutane pyrimidine dimers (CPDs) and photoproducts (6-4 PPs) in addition to immunosuppression mechanisms. ${ }^{3}$ Evidence suggests that UVB is more likely absorbed in the basal layer of the epidermis through the stratum corneum, while UVA penetrates further into dermal layers (e.g. stroma). ${ }^{12}$ UVB is uniquely implicated in direct mutagenesis involved in cutaneous melanoma via $\mathrm{C}>\mathrm{T}$ base changes following photochemical reaction.

Animal and fish models which incorporate UVB mimics find that UVB exposure can induce cutaneous melanoma. ${ }^{9,13}$ Prenatal exposure to UVB photo-mimics in animal models were originally considered necessary in the induction of cutaneous melanoma. Modern research has found that induction of cutaneous melanoma via UVB sources can take place even after adolescence. ${ }^{14}$ While UVB is a likely motivator in melanomagenesis, there remain questions as to the precise mechanisms which initiate conversion of at risk cells. For instance, authors have noted that although UVB can alter DNA directly through CPDs, DNA modification often occurs at the 3'end of the strand. ${ }^{13}$ Such unexpected outcomes 
may warrant additional exploration into the particular pathways implicated in cutaneous melanoma induction.

UVB is a popular explanatory mechanism for increased relative risk for cutaneous melanoma following acute sunburns. It is suggested that while cutaneous melanoma risk is modestly associated with cumulative solar exposure and sun burn jointly, the risk conferred by multiple sunburns, or periods of high intermittent UV exposure, especially in youth, are significant risk factors, with risk increasing as the quantity of lifetime sunburns increases. ${ }^{14,15}$ Per meta-analysis performed by Dennis et al. ( $\mathrm{N}=104$ studies) sunburn exposure significantly increased a subject's overall risk (OR) of cutaneous melanoma - OR was further stratified by age $($ Childhood $=1.8$, OR Adolescence $=$ 1.7 , OR Adulthood $=1.5$ ) with the youngest populations afflicted with the highest overall risk following sunburn. ${ }^{15}$ There is some evidence to suggest that senescent populations face outsized sunburn risk. ${ }^{16}$ While UVB is an impressive catalyst in cutaneous melanoma induction, UVA's acute role in the pathogenesis of cutaneous melanoma renders it difficult to disentangle one form of UVR from another as a causal variable in the aftermath of acute sunexposure. Furthermore, it is estimated that direct DNA damage-induced cutaneous melanoma can only account for $\mathrm{X}<8 \%$ of all cutaneous melanoma cases; $92 \%$ is attributed to indirect DNA damage. ${ }^{17}$

\section{UVA}

Initially, multiple models disputed the role of UVA in the induction of cutaneous melanoma. ${ }^{18}$ UVA radiation was considered insufficient in order to alter DNA bases via cyclobutane pyrimidine dimers (CPDs) and 6-4 photoproducts. ${ }^{9,13,18}$ Transgenic mouse models, the American opossum, and the xiphforous-fish were recruited in support of this hypothesis. ${ }^{10,19-20}$ Later findings would dispute these results, demonstrating the ability of UVA to initiate cutaneous melanoma in multiple animal models via oxidative stress. ${ }^{9}$ UVA is thought to induce cutaneous melanoma indirectly through reactive oxygen species (ROS) and immunosuppression. ${ }^{21-23}$ In particular, it has been proposed that melanin acts as the key photosensitizer in the pathogenesis of cutaneous melanoma via ROS. ${ }^{18}$

UVA's role in the pathogenesis of cutaneous melanoma appears infrequently contested in modern literature. Current estimates suggest that relative abundance and penetration of UVA is $\sim 20 \mathrm{x}$ and $\sim 90 \mathrm{x}$ greater than UVB in both atmospheric abundance and penetrative capacity respectively. ${ }^{24}$ And, while UVB may directly influence DNA mutagenesis, it is unable to penetrate deep dermal layers, beyond the stratum corneum. UVA, however, can penetrate well into the upper layers of the dermis/epidermis (beyond $100 \mu \mathrm{m}$ ) interacting with key target cells, including melanocytes. ${ }^{18}$ Accordingly, increased nevus count is associated with UVA exposure. ${ }^{25}$ UVA's ability to generate cutaneous melanoma indirectly through ROS was proposed as explanatory in the Sunscreen Paradox (SP).

The Sunscreen Paradox (SP) refers to findings at the turn of the millennium whereby it was observed that sunscreen use was positively associated with cutaneous melanoma. ${ }^{14,26}$ In recent years, the SP phenomenon has simmered with findings pointing to an agnostic link between prophylactic use of broad spectrum SPF and incidence of cutaneous melanoma. A particularly vivid meta-analysis illustrates precipitously declining relative-risk (RR) values - or the risk differential between exposed or unexposed groups - over the last two decades vis-a-vis the SP 
phenomenon. ${ }^{27}$ We agree with previous authors and propose that abatement of SP is resultant from the adoption of higher SPF, broad-spectrum sunblocks that target UVA/UVB in tandem. While early sunblocks focused on prevention of acute sunburn (conventionally associated with UVB) modern broad-spectrum composites target both UVA \& UVB. ${ }^{18,} 27$ It should be noted that other reviews have proposed alternative explanations for the SP phenomenon, including increased ROS production owing to radical-producing interactions between metal oxides in sunscreen and UVA/UVB. ${ }^{28}$ Authors remark that although sunscreen is marketed as a benign prophylactic, it is unable to dissipate excitation. ${ }^{28}$ Thus, subcutaneous sunscreen may magnify the impact of UVR on target cells. The SP is a significant phenomenon that merits further attention. This review briefly discusses its occurrence to evidence the role of UVR as an exogenous driver of cutaneous melanoma.

Evidence for the unique role of UVA in the pathogenesis of cutaneous melanoma is not isolated to the SP phenomenon. Further support for its paramount role in melanomagenesis can be found in epidemiologic data concerning the rise of popular indoor tanning devices (ITDs), or artificial sources of UVA induced radiation therapy for cosmetic enhancement of pigmentation. Indoor tanning devices rose to prominence in the early 1980s and 1990s. Concomitant with their rise were higher incidences of both cutaneous melanoma and non-melanoma skin cancer (NMSC), though paradoxically no increase in skincancer related mortality was observed. ${ }^{29}$ Several papers have attempted to explain this apparent paradox, with one proposing the existence of separate species of cutaneous melanoma - superficial spreading types chiefly resultant from extreme UVA exposure to melanocytes in adolescence and adulthood and more invasive types that arise from UVB exposure to melanocytes altered in adolescence and early adulthood. ${ }^{29}$ Epidemiologic data marshalled in support of this hypothesis has failed to reject such findings. ${ }^{30,31}$

Indoor tanning devices, such as tanning beds, are significantly associated with cutaneous melanoma, especially if used before the age of $35 .{ }^{32,33}$ Moreover, RR associated with cutaneous melanoma induction appears dose-dependent, with the $\mathrm{RR}$ associated with cutaneous melanoma increasing by as much as 3.8\% per tanning session. ${ }^{34}$ It is estimated that sunbeds deliver as much as 5-15x UVA doses than that delivered by "midday sun" in the Mediterranean $\left(31^{\circ}\right.$ - $40^{\circ}$ latitude). ${ }^{29}$ ITDs appear strongly associated with cutaneous melanoma incidence. Multiple findings document significantly increased cutaneous melanoma risk following use of ITD facilities. ${ }^{35}$ Incidence rates of cutaneous melanoma following the introduction of ITDs and facilities presage increased rates of cutaneous melanoma diagnosis. Extent evidence suggests that ITDs are a powerful exogenous driver of cutaneous melanoma. ${ }^{36}$ Thus, UVA's performance in the pathogenesis of cutaneous melanoma may be considered both relevant and significant.

A final insight concerning UVA's distinct role in the pathogenesis of cutaneous melanoma can be found in the asymmetric lateral distribution of cutaneous melanoma and Merkel Cell Carcinoma (MCC). It is reported that the typical "driver windshield" is unable to efficiently block longer wavelengths such as UVA, though UVR shielding varies between front, rear, and driver's side windshields. ${ }^{37}$ The latter being the most porous with respect to UVA, estimated to allow up to $30 \%$ of emitted UVA through its 
surface. ${ }^{38}$ Glass is able to effectively shield from shorter wavelength sources of radiation such as UVB, but not UVA. Anecdotally, it has been observed that truck driver's (transportation carriers more generally) may be at higher risk for cutaneous melanoma. The subject, though of clinical interest, represents a lacuna in the current literature. A recent study by Paulson, lyer, et al. demonstrated a marked difference in the lateral distribution of malignant melanoma (MM) and MCC. ${ }^{39}$ MMs and CCs were more likely to appear on the driver's left (53\% v. 47\%). ${ }^{40}$ Left-side bias was highly significant. ${ }^{39}$ It should be noted that UV exposure on the left-side of the driver's face is estimated at $20 \mathrm{x}$ in comparison to rightsided facial exposure of the driver. ${ }^{39}$ Further inquiry into the matter appears prudent.

\section{UVR Confounding}

UVR's collective role as an exogenous driver of melanoma is manifest, though perhaps not definitive. For instance, while UVR can be causally associated with induction of cutaneous melanoma, there likely exist endogenous genetic interplays that moderate its influence. A variety of loci have been found that significantly increased cutaneous melanoma risk, independent of solar exposure. CDKN2A, M1CR, NRAS and $B R A F$ are perhaps the most notorious agents considered involved in the pathogenesis of melanoma. ${ }^{13}$ CDK2NA were identified by investigators tracking subjects afflicted with Familial Atypical Multiple Mole Melanoma Syndrome (FAMMM). Both variants pertain to mitotic division, death, and senescence. ${ }^{41,42}$ It is thought that carriers of these variants are particularly susceptible to solar exposure and may experience adverse reactions to prolonged sun exposure. Other genetic disorders pertaining to nucleotide excision repair (NER) must be factored into any equation that attempts to assess the effect of solar radiation on cutaneous melanoma incidence. NER mutations are characterized by global failure to repair DNA damage resulting from solar radiation exposure. ${ }^{43}$ Examples of disorders characterized by NER defects include but are not limited to Xeroderma Pigmentosum (XP), trichothiodystrophy (TTD), and Cockayne Syndrome. ${ }^{18}$ It is beyond the scope of this paper to precisely estimate the impact of the aforementioned variants in the induction of cutaneous melanoma (though there is ample research which attempts to answer just that). In fact, a recent analysis of epigenetic interaction estimated the impact of UVrelated photo-damage in populations with alleles linked to melanoma incidence, concluding that individuals with abnormal variants with respect to MITF E318K, MC1R R-alleles, and the ASIP risk haplotype were more likely to exhibit multiple primary melanomas (MPMs) than controls (OR = 1.4-2.5).44 These considerations are broached to add dimensionality to our analysis. While UVR is almost assuredly a powerful exogenous driver of cutaneous melanoma, its role is complicated by genetic and hereditary confounds.

Indeed, UVR's role in the pathogenesis of cutaneous melanoma remains unclear in certain contexts. It has been noted that cutaneous melanoma appears in areas not directly exposed to UVR, though UVR is considered an explanatory factor. Scalp melanomas, for instance, have been linked to high levels of cumulative UVR exposure, signal a less optimistic prognosis and appear typically in senescent populations likely to have absorbed higher-than-average cumulative doses of UVR. ${ }^{45}$ The direct mechanism implicated in the exogenous pathogenesis of cutaneous melanoma in non-sun exposed regions remains illusory. ${ }^{46}$ It may be of clinical interest that incidence rates of head and neck melanomas have 
increased amongst younger populations in recent years, notably males (18-29). ${ }^{47}$ Higher UVR exposure has been proposed as a plausible explanatory factor. ${ }^{47}$ Though absolute rates of head and neck melanoma tilt significantly towards male populations $x>$ 50 years, such developments complicate extent theories regarding UVR exposure and the pathogenesis of cutaneous melanoma.

Additional confusion arises from clinical research suggesting that "sun exposure" in light skinned individuals "prone to tanning" (phototype II -- "unexposed skin is white, Blue, hazel or brown eyes Red, blonde or brown hair, European/Scandinavian, phototype III -- "Unexposed skin is fair, Brown eyes, Dark hair, Southern or Central European") may actually be protective against the incidence of melanoma. ${ }^{48,49}$ The link between UVR exposure and realized UVR exposure is mediated by absorption ability, specifically relative concentrations of pheomelanin and eumelanin. Pheomelanin and eumelanin are melanin subtypes linked to differential expression of the melanocortin-1 receptor (MC1R). Whereas concentrations of pheomelanin are roughly equivalent in most populations, relative concentrations of eumelanin differ considerably, with higher phototypes expressing more eumelanin than lower phototypes. $^{3} \quad$ Subjects with lower concentrations of eumelanin tend to be at higher risk for cutaneous melanoma as well as NMSCs (ibid). ${ }^{3}$ It is thought that eumelanin protects against melanoma promoting nutrient photolyases (e.g. folate). ${ }^{28}$ In this respect, identical UVR exposure may result in vastly disparate realized doses of UVR and differential degrees of noisome exposure.

Other such examples include the case of atypical nevi, also known as a dysplastic nevus (DN). UVR contribution to cutaneous melanoma can also be explained by its role in the genesis of dysplastic nevi, or Clark nevi. The dysplastic nevus is a term coined by Clark and his colleagues in 1978, initially referred to as B-K syndrome (eponymously inspired by families observed with morphological characteristics associated with dysplastic nevus syndrome). ${ }^{50} \mathrm{DN}$ is a complex and fraught subject in the field of dermatology. DNs are considered technical precursors to cutaneous melanoma due to their striking similarity to cutaneous melanoma in cytologic and histologic appearance. ${ }^{51}$ DNs are highly associated with cutaneous melanoma. It is estimated that the RR conferred by the presence of more than 5 atypical nevi ranges from 6.112.4. ${ }^{41}$ Yet, DNs have a remarkably low conversion rate to CMs. Current findings suggest that conversion rate of DN in men is $0.03 \%$ and $0.009 \%$ in women. ${ }^{41}$ Conversely, it is estimated that $\sim 20 \%$ of melanomas begin as DNs. ${ }^{41}$ UVR is pointed to as a distinct factor that is sufficient, but not necessary to the de novo genesis of DNs. ${ }^{52}$ The molecular dialogue amongst genetic and environmental constituent factors contributes to the complexity surrounding precise attribution of UVR to the induction of cutaneous melanoma.

\section{OTHER EXOGENOUS FACTORS}

Hormones \& Cutaneous Melanoma

Cutaneous melanoma risk and hormonal supplementation, especially as it relates to oral contraceptives (OCs) and Hormone Replacement Therapy (HRT), is a contentious subject in modern literature, with a variety of studies reporting contradictory findings. Initial findings presented by Ellerbroek (1968) and Beral (1977) separately reported that history and $\mathrm{OC}$ use were associated with increased risk of 
cutaneous melanoma. ${ }^{53,54}$ In addition, epidemiologic data has consistently reported increased incidence of cutaneous melanoma in women, but not men, 25-29 years of age. ${ }^{55,56}$ It was suspected that OCs were significant explanatory factors.

A large-scale review of the subject was subsequently undertaken by Hannaford, Mackintosh, et al. (1991) leveraging data derived from the Royal College of General Practitioners and the Oxford Family Planning Association. Amassing over 23,000 subjects, the institutions reported no clinically significant association between $R R$ of cutaneous melanoma and use, history, or duration of oral contraceptive use. ${ }^{57}$ The Royal College of Practitioners' Study did report an increased risk of cutaneous melanoma associated with OCs, however, that finding failed to achieve statistical significance. ${ }^{57}$ The report by the RCP criticized previous findings, indicating that sample sizes were insufficient and UV exposure remained poorly controlled, acting as a potential confounder. In the last several decades, research pertaining to the use and impact of OCs on incidence of cutaneous melanoma has been the subject of routine debate. $^{58}$ The preponderance of studies indicate that while OCs are typically associated with cutaneous melanoma, that relationship is weak and is mitigated when proper controls are integrated. ${ }^{59,60}$ Adjusting for UVR exposure and phenotypic risk factors depresses reported associations. Cervenka and Saleh et al. reviewed data gathered from a French cohort comprising 79,365 women from 1992-2008, reporting that $\mathrm{OC}$ use was not strongly associated with cutaneous melanoma. ${ }^{61}$ Results of the cohort study suggest that $\mathrm{OC}$ use, strength, and duration increase $\mathrm{RR}$ for cutaneous melanoma, but that risk fails to achieve statistical significance once the researchers controlled for UVR. The team concludes that there exists little evidence linking OC use to increased incidence of cutaneous melanoma. Rather, increased associations may be explained by intentional UVR exposure amongst $\mathrm{OC}$ users. A subsequent analysis by Cervenka, Al Rahmoun, Mahamat-Saleh et al. replicated prior findings, with the exception that the team reported a "border-line" positively significant relationship between OC use and melanoma, with a linear increase associated with duration of $\mathrm{OC}$ use. ${ }^{62}$ The team reaffirms that there exists no strong evidence linking hormonal supplementation to cutaneous melanoma. ${ }^{62}$ Additional large scale inquiries into the matter have produced concordant findings. ${ }^{56}$ A notable, recent exception was documented by Koomen, Joose, et al. reporting that OC use, dosage, and duration of OC use was strongly associated with cutaneous melanoma incidence. ${ }^{63}$ Results of this study may be considered limited as a result of insufficient data regarding confounds, particularly UVR exposure amongst reported subjects.

Findings regarding the impact of Hormonal Replacement Therapies (HRTs) on the incidence and induction of cutaneous melanoma report similar findings. ${ }^{59}$ HRTs do not appear to be strongly implicated in the induction of cutaneous melanoma. ${ }^{64}$ HRT refers to supplementation, typically of oestrogen and progestin, in target groups following menopause. HRTs were implicated in the induction of cutaneous melanoma following inquiry into the supposed link between OCs and cutaneous melanoma. Associations appear to be tenuous and significant associations are typically achieved when stratifying populations by age (e.g. 30-40 ya), OC duration (e.g. $x>10$ years), and marked sun exposure. ${ }^{65,66}$ Gandini, lodice, et al. summarize data in a large-scale review encompassing 36 
observational studies and 5626 confirmed cases of cutaneous melanoma. ${ }^{59}$ The group report that HRTs (in addition to OCs) were not significantly associated with cutaneous melanoma risk. ${ }^{59}$ However, age at first birth appeared to be a significant risk factor for cutaneous melanoma. Various reviews have arrived at similar conclusions. ${ }^{59,67}$, One exception lies in a review by Botteri, Stoer, et al. which assesses the impact of cutaneous melanoma risk conferred by HRTs. The authors conclude that there exists a significant, positive relationship between HRT and cutaneous melanoma $(R R=1.44) .68$ The authors caution that estrogen and progestin may exhibit disparate, competing effects. ${ }^{68}$ The latter may serve as a protective factor in the pathogenesis of cutaneous melanoma. ${ }^{69,70}$ While the study estimates the impact of UVA on a Norwegian cohort, their estimates for exposure depend on an estimate for UVA exposure according to spatial location. Thus, confounds for increased exposure among HRT users presents a salient limitation. It should be noted that other explorations into the matter have reported contrary findings, suggesting that the effects born of HRT supplementation do not differ by selected hormone type. ${ }^{71}$ In a recent review of epidemiologic data from a large European cohort, Cervenka, Al Rahmoun, MahamatSaleh et al. document a nonsignificant increase in OR associated with cutaneous melanoma incidence. ${ }^{62}$

While modern findings point away from a direct, or rather agnostic link between $\mathrm{OC}$ use HRT and cutaneous melanoma incidence, the potential role for hormones in the pathogenesis of cutaneous melanoma remains conceivable. For example, animal experiments provide evidence to support the role of estrogen in the proliferation of melanocytes and the production of melanin. ${ }^{72}$ It may be of clinical interest, too, that periods of hormonal saturation (e.g. pregnancy) are associated with various topical manifestations of melanocyte activity including but not limited to changes in size and relative frequency of naevi, formation of the linea nigra and appearance of acute melasma in pregnant subjects. ${ }^{73,74}$ Several studies investigating the effect of pregnancy on cutaneous melanoma mortality have concluded that melanoma prognosis does not significantly differ between pregnant and non-pregnant controls. ${ }^{75,76}$ However, the age at first and last birth have been linked to incidence of cutaneous melanoma, as has the number of offspring. ${ }^{59,77} \mathrm{~A}$ recent metaanalysis conducted by $\mathrm{Li}, \mathrm{Gu}$, and Cen (2015) assessing the relationship between cutaneous melanoma and age at birth, documented an increased risk associated with age at first birth (pooled $R R=1.44$ ) and declining risk with respect to number of offspring $(X>1) .{ }^{67}$ Upon meta-analysis, subjects reporting advanced age at first birth were subject to increased cutaneous melanoma risk, as were those with later ages at first birth. ${ }^{67}$ The authors caution that such an association is contestable and has not been universally replicated. ${ }^{67}$ Yet, cutaneous melanoma response to hormonal fluctuation is complicated by the finding that estrogen receptor positive patients do not respond to antiestrogens or oophorectomy; in contrast, nearly $67 \%$ of estrogen-receptor positive breast cancer patients respond to identical treatments. ${ }^{78}$ Such findings invite further research into the precise mechanisms implicated in the interplay between hormonal fluctuation and cutaneous melanoma.

Potential areas for exploration may target the differential effects exerted by different dermal subtypes of estrogen receptors in cutaneous melanoma prognosis. $^{79}$ For example, Estrogen-receptor Beta ( $\boldsymbol{\varepsilon R B})$ concentrations in the tumor

May 2020 Volume 4 Issue 3 
microenvironment were predictive of prognosis. ${ }^{80}$ Higher relative $\varepsilon$ RB concentrations were associated with decreased tumor proliferation and were inversely related to Breslow depth. ${ }^{81}$ On the other hand, its sister receptor, Estrogenreceptor Alpha $(\varepsilon R A)$, was positively associated with proliferative activity. ${ }^{79}$ Such findings may be explanatory in mortality specific discrepancies between male and female subjects at nearly all stages of cutaneous melanoma prognosis. More intriguing is marked differences in survival rates between post- and pre-menopausal subjects, the latter being associated with improved prognosis. ${ }^{56}$

Other areas for clinical exploration may involve interactions between circulating hormones and solar radiation. While controlling for UVR exposure reduced associations reported between cutaneous melanoma incidence in subjects taking OCs and HRTs, it could be the case that UVR and estrogen exert interactive effects that magnify relative risk of cutaneous melanoma incidence. It is beyond the scope of this paper to evaluate the veracity of these claims.

\section{Dietary Factors, Obesity, Smoking \& Vitamins}

Dietary risk factors implicated in the induction of cutaneous melanoma are seldom identified in present literature. Exogenous cases of cutaneous melanoma linked to dietary factors do not appear pronounced at present. The dearth of available evidence may be the result of faulty design, poor controls, or a want of inquiry into the matter.

A notable exception to this finding is reported alcohol consumption. Consumption of ethanol related beverages is associated with significant increases in cutaneous melanoma risk. ${ }^{82-84}$ Relevant associations between alcohol and cutaneous melanoma risk are documented within multiple analyses in the last several decades. William et al. (1977), Holman et al. (1986), Stryker et al. (1990), Millen et al. (2004), and Rivera et al (2016), document significant associations between alcohol consumption and cutaneous melanoma risk. ${ }^{82,84-87}$ OR risk estimates vary considerably with Holman reporting a OR value of $\sim 2$ associated with 4 or more drinks per week, while Millen generate OR estimates of 1.65 associated with 1.4 drinks per week, and Rivera et al. report OR associated with alcohol intake of 1.4 for those in the highest quintiles of consumption ( $x>20$ units of alcohol per day). ${ }^{82,84,86}$ It should be noted that several studies have also failed to replicate findings demonstrating a link between alcohol consumption and melanoma risk. ${ }^{88,89}$ Thus, there appears to be a probable but not definitive link between alcohol consumption and cutaneous melanoma.

The mechanisms underlying increased cutaneous melanoma risk are typically ascribed to DNA adducts as a result of acetaldehyde formation, ROS species generation, inflammatory factors, and epigenetic interactions with respect to histone methylation and acetylation. 82,90,91 $^{-1}$

A more in-depth analysis of the specific pathways involved in cutaneous melanoma induction resultant from ethanol intake were described by Rivera et al. (2016). ${ }^{82}$ Leveraging meta-data from a three-cohort study, the team find evidence of an increased risk of cutaneous melanoma following ethanol consumption, reporting pooled-risk of 1.14 for all groups. ${ }^{82}$ The authors remark that the melanomagenic properties attributed to alcohol derive from acetaldehyde induced DNA adducts and potential photosensitization mechanisms. ${ }^{82}$ 
In accordance with these findings, the authors suggest that greater risk conferred to females, as opposed to males, of cutaneous melanoma risk attributable to alcohol consumption is the result of greater effective concentrations of acetaldehyde reaching melanocytes in female subjects. ${ }^{82}$ Additionally, forms of ethanol containing higher effective doses of acetyl-aldehydes were more strongly associated with melanoma risk (e.g. white wine). ${ }^{82}$ An interesting feature of the team's study observed that incidence of melanoma in-situ was strongly correlated with alcohol consumption on non-sun exposed sites, as opposed to only modest associations reported in sun-exposed sites. ${ }^{82}$ Acetaldehyde penetration of melanocytes and its secondary genotoxic effects seems a potential candidates for exploration.

Obesity, more generally excess BMI, is cited as a risk factor in a number of carcinomas. ${ }^{92}$ Evidence establishing a connection between cutaneous melanoma and obesity is scant. For instance, one of the few notable studies to explore this question was undertaken by Sergentanis et al. (2013). ${ }^{93}$ The team reports that excess $\mathrm{BMI}$ is a significant risk factor for cutaneous melanoma (pooled $\mathrm{OR}=1.31$ ) in males but not females. ${ }^{93}$ The researchers cautioned that while no significant association was found among females with gratuitous BMI, it still may be a relevant factor for consideration. ${ }^{93}$ It may be of clinical interest that patients with excess BMI, notably males, tend to have a better prognosis once diagnosed with melanoma, and other cancers more generally. ${ }^{94}$ Obesity, especially in males, is linked to higher levels of ambient estrogen. ${ }^{95}$ The obesity paradox (OP) may hark back to an earlier discussion of the role played by estrogen in the suppression of tumorigenesis and proliferation in cutaneous melanoma via $\varepsilon R B$ concentrations.
Smoking, almost by definition, is linked to a spate of highly lethal carcinomas. ${ }^{96}$ Evidence linking smoking to cutaneous melanoma is absent, with separate analyses failing to report significant associations. ${ }^{97-99}$ In fact, case control studies identified report insignificant, but inverse, associations between smoking and cutaneous melanoma risk. ${ }^{100}$ There is some discussion that smoking may, surprisingly, act as a protective factor in the induction of cutaneous melanoma. ${ }^{96}$

While this paper does not focus on protective exogenous factors connected to cutaneous melanoma risk, we note that there exists ample evidence linking waning cutaneous melanoma risk to higher serum levels of carotenoids (e.g. beta-carotene), flavonoids, polyphenols, alpha-tocopherol (Vitamin E), retinol (Vitamin A), resveratrol, pomegranate extract, and regular coffee consumption. ${ }^{101-105}$ The effects born of the aforementioned supplements are numerous and manifold, but include reparation of UVR induced damage, regulation of apoptosis, decreased proliferation, and enhanced differentiation. ${ }^{106}$ Cutaneous melanoma patients reporting higher serum concentrations of Vitamin D, in particular, were reported to have a superior prognosis following diagnosis, especially in metastatic subjects. ${ }^{107.108}$ Those subjects that routinely consumed coffee enjoyed reductions in cutaneous melanoma risk $(\mathrm{OR}=0.75) .{ }^{109-111}$ In a large prospective cohort ( $n=69,635)$, Vitamin A (retinol) appeared to exert a significant chemopreventive benefit in subjects reporting current oral supplementation. It should be noted that upon analysis of the relevant literature, the authors note that such findings accord with some but not all current findings. ${ }^{112}$ In a meta-analysis of supplementation findings related to melanoma induction, Russo et al. document chemopreventive benefits 
associated with Vitamin E (alphatocopherol), Vitamin D (cholecalciferol), Vitamin-C (ascorbic acid), and Vitamin $\mathrm{K}$ (potassium). ${ }^{108}$

Dietary factors implicated in the induction of cutaneous melanoma are limited and typically involve alcohol consumption. Smoking and Obesity were considered as potential risk factors. Obesity remains a plausible candidate for exogenous risk, while smoking does not appear strongly correlated with cutaneous melanoma. It should be mentioned that the above factors, while prominent, confer markedly lower risk for cutaneous melanoma in comparison with traditional risk factors such as UVR.

\section{lonizing Radiation ( $X=125 \mathrm{~nm}$ )}

Incidence of cutaneous melanoma as a result of ionizing radiation is another topic bereft of broad exposure in current research. While ionizing radiation is a well-established mutagen, its role in the induction of cutaneous melanoma is dubious. It is known that shorter wavelengths (e.g. $x<280$; e.g. UVC (200-280nm)) can induce cutaneous melanoma in bombarded subjects. ${ }^{13}$ Cohort analyses of ionizing-radiation related occupations evidence increased risk of cutaneous melanoma. ${ }^{113}$ We examine data concerning the effect of ionizing radiation on melanomagenesis provided by four relevant working papers.

One of the first reports linking to cutaneous melanoma to ionizing radiation was observed by Donald Austin \& Reynolds (1994). ${ }^{114}$ The duo, in response to an outsized incidence of melanoma cases (four-fold incidence in comparison with average population) at the Lawrence Livermore National Laboratory in Alameda County, engaged in a study which sought to determine if chronic exposure to ionizing radiation was sufficient to explain this outcome. ${ }^{114}$ Multivariate analysis revealed significant risk $(\mathrm{OR}=3.0)$ for cutaneous melanoma associated with ionizing radiation. ${ }^{114}$ The authors note that while chance may explain this finding, it is doubtful. ${ }^{114}$

Their conclusion stems from the following factors: "incidence was disproportionately greater amongst laboratory workers than would be expected in standard population models"; the data accord with previous findings by Pion et al. (1995), Mantanoski \& Seltser et al. (1975), Caldwell \& Kelly et al. (1983), Hadjimichael \& Ostfeld et al. (1983), Wright \& Peters (1983); "stratifying by specific occupation" (e.g. chemist) and even "ever/never" radiation exposure significantly increased cutaneous melanoma risk, among other factors. ${ }^{114}$ Intriguingly, the duo add nuance to their discussion, adding that the absence of measurable dose-response findings in tandem with "other identified occupational risk factors" support the hypothesis that high single dose cases of ionizing radiation may be explanatory. ${ }^{114}$

In response to concerns voiced by Austin \& Reynolds, Fink \& Bates (2005) would conduct an epidemiological review to assess incidence of melanoma among several groups - "(1) The Canadian Radiation Dose Registry, (2) nuclear industry workers, (3) subjects near nuclear test blasts, (4) survivors of the atomic bombings of Japan, (5) airline pilots and cabin attendants, (6) recipients of medical radiation, and (7) radiological technicians." 115 The researchers report that subjects that were more likely to develop leukemia related to radiation exposure appeared to be similarly at risk for melanoma. ${ }^{115}$ The authors caution that there could exist unexplored confounds, such as UVR exposure. In its absence, however, a causal relationship is possible, thereby 
adding credence to the hypothesis propounded by Austin \& Reynolds. ${ }^{114}$

Later reviews evidence the role of ionizing radiation in the pathogenesis of cutaneous melanoma. Friedman, Sigurdson, et al. (2003) document increased risk of melanomagenesis among radiation technicians/radiation related workers exposed to low, chronic levels of ionizing radiation, especially those practicing before 1950 and those who opted against protective materials. ${ }^{106}$ The report surveyed 68,588 radiologic technicians, all caucasian and $\sim 70 \%$ female. The authors note that other studies evaluating the relationship tend to rely on fatality rates. Such studies, they caution, may lead to underreporting associations among certain low-fatality diseases (e.g. melanoma). ${ }^{116}$

Conversely, in a more recent review, Azizova, Bannikova, and Grigoryeva (2018) survey 22,377 individuals, finding that cutaneous melanoma risk is not modified by exposure to ionizing radiation. ${ }^{117}$ The cohort is comprised of Russian nuclear production facility personnel and Mayak Production Association personnel from 1948-1982. The cohort was tracked until the end of 2013. The authors observe that the incidence of Non-melanoma Skin Cancer (NMSC) is significantly associated with cumulative gamma ray exposure greater than $2.0 \mathrm{~Sv}$ (2000 mSv). No such association was found with cutaneous melanoma. ${ }^{117}$ The mechanisms by which ionizing radiation exerts differential effects with respect to NMSC and cutaneous melanoma presents an avenue for future exploration.

Few papers focus on the link between ionizing radiation and melanoma. Most are epidemiologic. None - that can be found - can prove causality, nor do they explore the molecular pathways proposed as explanatory. It is possible that ionizing radiation is associated with melanoma, however, the precise cascade initiated by ionizing radiation in the induction of cutaneous melanoma remains unresolved.

\section{Chemicals \& Pollution}

The link between exposure to various chemicals and pollutants and the pathogenesis of cutaneous melanoma is well-documented in modern literature. The trove of synthetic contributors to cutaneous melanoma induction include, but are not limited to: polycyclic achromatic hydrocarbons (PAHs), polychlorinated biphenyls (PCBs), polyvinyl chlorides (PVCs), Levodopa (L-dopa), heavy-metals (e.g. nickel, lead), asbestos, localized trauma (e.g scar-tissue), Volatile Organic Compounds (VOCs, e.g. benzene), insecticides (e.g. carbaryl, parathion, \& toxaphene), and fungicides (e.g. maneb). Evidence establishing the connection between the above exposure-types and cutaneous melanoma derives from animal models, occupational cohort studies, and meta-analyses. ${ }^{78}$

Theories which attempt to explain chemical/pollutant induced cutaneous melanoma are varied. Primary explanations include the melanin-affiliated hypothesis of mutagenesis. Larsson (1993) reports that it is known that melanin exhibits strong binding affinities for percutaneously leached substances, especially organic amines and metal ions. ${ }^{118}$ As a result, local concentrations of various chemicals/pollutants aggregate in melanocytes leading to eventual histologic abnormalities after cumulative exposure. ${ }^{118}$ More specific explanations are reported by Rockley et al. (1994) who suggest that chemical induction of cutaneous melanoma can be attributed to: (1) the binding of chemical/pollutants to keranocytic DNA and additional macromolecules; (2) promotion of 
"cytochrome P-450 activities;" (3) activation of protein kinase $-\mathrm{C}$, which the authors note lead to "deregulation of cellular growth and differentiation". ${ }^{78}$ Alternative routes of chemical/pollution related cutaneous melanoma induction are thought to arise from systemic reductions in cellular immunity. ${ }^{78}$ We will review several associations most prominent in the literature.

PAHs present a powerful driver of chemicalrelated cutaneous melanoma induction. PAHs are pyrolytic by-products typically found in tar, oil-products, soot, anthracene, pitch, and creosote. $^{78}$ Specific $\mathrm{PAH}$ derivatives tied to cutaneous melanoma induction include 7,12-dimethylbenz-(a)anthracene (DMBA), 5,9,10-trimethyl-I, 2benzanthracene, and coal tar derivatives. ${ }^{119}$ Rockley et al. relay findings reported by Edgecomb \& Mitchelich (1963) and Della \& Report (1956) documenting nevus proliferation and cutaneous melanoma linked to application of DMBA in animal models. ${ }^{78}$ Occupational exposures to PAHs are associated with a significantly increased risk of cutaneous melanoma. ${ }^{120}$ In a largescale meta-analysis of cutaneous melanoma incidence among oil-refinery workers, Mehlman (2006) reports significant risks attributed to oil-refinery occupation (OR = 1.1- 6.7). ${ }^{121} \mathrm{PAHs}$ are prominent pollutants present in petrochemical refineries. When stratified by occupation (i.e. exposure to PAHs, PCBs, benzene, asbestos \& heavy oils) OR risk values rise. ${ }^{121}$ The author notes that there exist disparate findings between industry sponsored studies and independent reviews, with the former reporting negative results. It is probable that negative findings are the result of industry bias. ${ }^{121}$ Occupational analysis of cutaneous melanoma incidence amongst fireman report increased cutaneous melanoma risk (OR = 1.21). ${ }^{122}$ The authors write that increased cutaneous melanoma risk may be resultant from excess PAHs, arsenic, among other carcinogenic substances that penetrate personal protective equipment (PPE). ${ }^{122}$ While it is difficult to prove - without confound - the effects ascribed to PAHs in occupational cohorts, their role in the pathogenesis of cutaneous melanoma appears likely.

PCBs have been similarly implicated in the induction of cutaneous melanoma. PCBs are found in coolants, manufacture of capacitors, pollutants in certain water supply systems, fire retardants, hydraulic fluids, cutting oils and as plasticizers in paints, cements, stabilizing additives in PVCs, among others. ${ }^{78}$ PCBs are a unique risk factor for cutaneous melanoma. For instance, plasma concentrations of PCB are associated - in dose dependent fashion with cutaneous melanoma risk. Subjects found with the highest serum concentrations of PCB were found to have significantly increased risk compared with controls $(\mathrm{OR}=$ 6.02 (dioxin PCB ) - 7.02 (non-dioxin PCB)). ${ }^{123}$ Bahn et al. reports increased cutaneous melanoma incidence among petrochemical workers exposed to greater concentrations of PCB. ${ }^{124}$ Brown \& Jones (1981) failed to find an increased risk of cutaneous melanoma mortality associated with low-levels of PCB exposure. ${ }^{125}$ In a systematic review and meta-analysis conducted by Zani, Ceretti, et al. (2017) PCB exposure was associated with higher standardized mortality incidence ratios (pooled SMR = 1.32). ${ }^{126}$ However, the authors conclude that there is not strong evidence to suggest that PCBs are implicated in the induction of cutaneous melanoma, although it is a risk factor. ${ }^{126}$ Taken together, the assortment of both negative and positive findings suggests that PCB related cutaneous melanoma induction is dependent on realized dose. 
Studies examining the role of fungicides and insecticides in cutaneous melanoma induction find likely associations. ${ }^{127}$ The fungicide, Maneb (polymeric dithiocarbamate), was implicated as a risk factor for cutaneous melanoma induction by Dennis \& Lynch et al. (2010) in a review of pesticide applicators in the Agricultural Health Study. ${ }^{128}$ Exposure to Maneb was found to increase cutaneous melanoma risk in a dose dependent manner ( $63>X$ à OR $=1.6) ;(X>63$ OR = 2.4) $) .{ }^{128}$ Insecticides documented to be linked to cutaneous melanoma risk include Toxaphene (insecticide organochlorine) $(\mathrm{RR}=0.7-2.9)$, Parathion (insecticide organothiophosphate) $(\mathrm{OR}=1.6-2.4)$, and Carbaryl (insecticide carbamate) $(\mathrm{OR}=1.3-1.7) .127,128$

Other chemicals and pollutants that have been reportedly associated with $\mathrm{C}$ cutaneous melanoma increase include asbestos, PVCs, Arsenic, L-Dopa, hydrocarbon solvents (e.g. formaldehyde) among others. Each factor is uniquely associated with cutaneous melanoma and is potentially causally linked to its induction. Rockley et al. (1994) document the gamut of associations attributed to the aforementioned factors in an extensive meta-review. Their work is compendious and should be revisited for further reference. ${ }^{78}$

In summary, a variety of exogenous chemicals and pollutants are probable agents in the exogenous induction of cutaneous melanoma. While this review specifically addressed PAHs, PCBs, Maneb, Toxaphene, Carbaryl, and Parathion there exist a panoply of other candidates for consideration that may, too, play a role in melanomagenesis.

\section{CONCLUSION}

This review has sought to identify and examine the various exogenous factors linked to cutaneous melanoma induction. The identification of potentially exogenous sources of cutaneous melanoma induction is crucial to the prevention of future cutaneous melanoma cases. While UVR is a permanent fixture of exogenous research into the induction of melanoma, this review endeavors to present additional candidates for consideration, explore their implications, and challenge prevailing attitudes regarding the attribution of cutaneous melanoma incidence to a particular exogenous source. What manifests is a broad and sweeping array of incident factors spanning UVA/UVB, Hormonal Supplementation, Dietary and Lifestyle related factors, Ionizing Radiation, Chemicals and Pollutants.

\section{Conflict of Interest Disclosures: None}

Funding: None

Corresponding Author:

Lawrence S. Moy, MD

1101 N Sepulveda Blvd \#100

Manhattan Beach, CA 90266

Phone: $310-546-7780$

Fax: 310-546-2440

Email: Ism.doc@me.com

References:

1. Refs US Department of Health and Human Services. The Surgeon General's Call to Action to Prevent Skin Cancer. Washington (DC): Office of the Surgeon General (US); 2014. Available from:

https://www.ncbi.nlm.nih.gov/books/NBK247172/

2. IARC Working Group on the Evaluation of Carcinogenic Risk to Humans. (1970, January 1). SOLAR AND ULTRAVIOLET RADIATION. Retrieved from https://www.ncbi.nlm.nih.gov/books/NBK304366/. 
3. D'Orazio, J., Jarrett, S., Amaro-Ortiz, A., \& Scott, T. (2013). UV radiation and the skin. International journal of molecular sciences, 14(6), 1222212248. https://doi.org/10.3390/ijms140612222

4. Jhappan, C., Noonan, F. \& Merlino, G. Ultraviolet radiation and cutaneous malignant melanoma. Oncogene 22, 3099-3112 (2003). https://doi.org/10.1038/sj.onc.1206450

5. Sample, A., \& He, Y. Y. (2018). Mechanisms and prevention of UV-induced melanoma. Photodermatology, photoimmunology \& photomedicine, 34(1), 13-24. https://doi.org/10.1111/phpp.12329

6. Watson, M., Holman, D. M., \& Maguire-Eisen, M. (2016, August). Ultraviolet Radiation Exposure and Its Impact on Skin Cancer Risk. Retrieved from

https://www.ncbi.nlm.nih.gov/pmc/articles/PMC50 36351/.

7. Kripke, M. L. (2013, June 21). Impact of Ozone Depletion on Skin Cancers. Retrieved from https://onlinelibrary.wiley.com/doi/abs/10.1111/j.1 524-4725.1988.tb03589.x

8. Fabo, E. C. D., Noonan, F. P., Fears, T., \& Merlino, G. (2004, September 15). Ultraviolet B but not Ultraviolet A Radiation Initiates Melanoma. Retrieved from https://cancerres.aacrjournals.org/content/64/18/ 6372.

9. Noonan, F. P., Zaidi, M. R., Wolnicka-Glubisz, A., Anver, M. R., Bahn, J., Wielgus, A., ... Fabo, E. C. D. (2012, June 6). Melanoma induction by ultraviolet $A$ but not ultraviolet $B$ radiation requires melanin pigment. Retrieved from https://www.nature.com/articles/ncomms1893.

10. von Thaler, A.-K., Kamenisch, Y., \& Berneburg, M. (2010, February). The role of ultraviolet radiation in melanomagenesis. Retrieved from https://www.ncbi.nlm.nih.gov/pubmed/20067521.

11. Wang, S. Q., Setlow, R., Berwick, M., Polsky, D., Marghoob, A. A., Kopf, A. W., \& Bart, R. S. (2001, May). Ultraviolet A and melanoma: a review. Retrieved from https://www.ncbi.nlm.nih.gov/pubmed/11312434.

12. Bruls WA, Slaper $H$, van der Leun JC, Berrens L. Transmission of human epidermis and stratum corneum as a function of thickness in the ultraviolet and visible wavelengths. Photochemistry and Photobiology. 1984 Oct;40(4):485-494. DOI: 10.1111/j.17511097.1984.tb04622.x.

13. Craig, S., Earnshaw, C. H., \& Virós, A. (2018, March 5). Ultraviolet light and melanoma. Retrieved from https://onlinelibrary.wiley.com/doi/full/10.1002/pat h.5039.
14. Viros, A., Sanchez-Laorden, B., Pedersen, M., Furney, S. J., Rae, J., Hogan, K., ... Marais, R. (2014). Ultraviolet radiation accelerates BRAFdriven melanomagenesis by targeting TP53. Nature, 511(7510), 478-482. doi: 10.1038/nature13298

15. Mulliken, J. S., Russak, J. E., \& Rigel, D. S. (2012). The Effect of Sunscreen on Melanoma Risk. Dermatologic Clinics, 30(3), 369-376. doi: 10.1016/j.det.2012.04.002

16. Dennis, L. K., Vanbeek, M. J., Beane Freeman, L. E., Smith, B. J., Dawson, D. V., \& Coughlin, J. A. (2008). Sunburns and risk of cutaneous melanoma: does age matter? A comprehensive meta-analysis. Annals of epidemiology, 18(8), 614-627.

https://doi.org/10.1016/j.annepidem.2008.04.006

17. Holman, D. M., Ding, H., Freeman, M. B., \& Shoemaker, M. L. (2019, May 17). Association Between Sun Protection Behaviors and Sunburn Among U.S. Older Adults. Retrieved from https://www.ncbi.nlm.nih.gov/pubmed/31100136

18. Davies, H., Bignell, G., Cox, C. et al. Mutations of the BRAF gene in human cancer. Nature 417, 949-954

(2002). https://doi.org/10.1038/nature00766

19. Leslie P. Lund, Graham S. Timmins, Melanoma, long wavelength ultraviolet and sunscreens: Controversies and potential resolutions, Pharmacology \& Therapeutics, Volume 114, Issue 2, 2007, Pages 198-207, ISSN 0163-7258, https://doi.org/10.1016/j.pharmthera.2007.01.007.

20. Cleaver, J. E., \& Crowley, E. (2002, April 1). UV damage, DNA repair and skin carcinogenesis. Retrieved from https://www.ncbi.nlm.nih.gov/pubmed/11897551/.

21. Ullrich, S. E. (2005). Mechanisms underlying UVinduced immune suppression. Mutation Research/Fundamental and Molecular Mechanisms of Mutagenesis, 571(1-2), 185-205. doi: 10.1016/j.mrfmmm.2004.06.059

22. Kamenisch, Y., Ivanova, I., Drexler, K., \& Berneburg, M. (2018, June 28). UVA, metabolism and melanoma: UVA makes melanoma hungry for metastasis. Retrieved from https://onlinelibrary.wiley.com/doi/10.1111/exd.13 561.

23. Khan, A. Q., Travers, J., \& Kemp, M. G. (2018, January 1). Roles of UVA radiation and DNA damage responses in melanoma pathogenesis. Retrieved from https://indiana.pure.elsevier.com/en/publications/ $r$ oles-of-uva-radiation-and-dna-damageresponses-in-melanoma-patho.

24. Lim, H. W., Naylor, M., Hönigsmann, H., Gilchrest, B. A., Cooper, K., Morison, W., ... May 2020 Volume 4 Issue 3 
Scherschun, L. (2003, May 19). American Academy of Dermatology Consensus Conference on UVA protection of sunscreens: Summary and recommendations: Washington, DC, Feb 4, 2000. Retrieved

from https://www.sciencedirect.com/science/article/abs /pii/S0190962201458762\#aep-article-footnoteid1.

25. Dulon, M., Weichenthal, M., Blettner, M., Breitbart, M., Hetzer, M., Greinert, R., ... Breitbart, E. W. (2002, November). Sun exposure and number of nevi in 5- to 6-year-old European children. Retrieved from https://www.ncbi.nlm.nih.gov/pubmed/12507670.

26. Wolf P; Quehenberger, F; Müllegger, R; Stranz, $\mathrm{B}$; Kerl, $\mathrm{H}$

27. Melanoma Research: August 1998 - p 370-378

28. Silva, E. S. D., Tavares, R., Paulitsch, F. D. S., \& Zhang, L. (2018). Use of sunscreen and risk of melanoma and non-melanoma skin cancer: a systematic review and meta-analysis. European Journal of Dermatology, 28(2), 186-201. doi: 10.1684/ejd.2018.3251

29. Volkovova, K., Bilanicova, D., Bartonova, A., Letašiová, S., \& Dusinska, M. (2012). Associations between environmental factors and incidence of cutaneous melanoma. Review. Environmental Health, 11(Suppl 1). doi: 10.1186/1476-069x-11-s1-s12

30. Autier, P., Doré, J.-F., Eggermont, A. M., \& Coebergh, J. W. (2011). Epidemiological evidence that UVA radiation is involved in the genesis of cutaneous melanoma. Current Opinion in Oncology, 23(2), 189-196. doi: 10.1097/cco.0b013e3283436e5d

31. Moan, J., Baturaite, Z., Porojnicu, A. C., Dahlback, A., \& Juzeniene, A. (2011, October 11). UVA, UVB and incidence of cutaneous malignant melanoma in Norway and Sweden. Retrieved from https://pubs.rsc.org/en/content/articlelanding/201 2/PP/C1PP05215B\#!divAbstract.

32. Hery, C., Tryggvadottir, L., Sigurdsson, T., Olafsdottir, E., Sigurgeirsson, B., Jonasson, J. G., ... Autier, P. (2010). A Melanoma Epidemic in Iceland: Possible Influence of Sunbed Use. American Journal of Epidemiology, 172(7), 762767. doi: 10.1093/aje/kwq238

33. Zhang, M., Qureshi, A. A., Geller, A. C., Frazier, L., Hunter, D. J., \& Han, J. (2012, May 10). Use of tanning beds and incidence of skin cancer. Retrieved from https://www.ncbi.nlm.nih.gov/pmc/articles/PMC33 83111/\#B7.

34. IARC Working Group on the Evaluation of Carcinogenic Risk to Humans. (1970, January 1).
SOLAR AND ULTRAVIOLET RADIATION. Retrieved from https://www.ncbi.nlm.nih.gov/books/NBK304366/.

35. Boniol, M., Autier, P., Boyle, P., \& Gandini, S. (2012, July 24). Cutaneous melanoma attributable to sunbed use: systematic review and meta-analysis. Retrieved from https://www.bmj.com/content/345/bmj.e4757.

36. Levine, J. A., Sorace, M., Spencer, J., \& Siegel, D. M. (2005, December). The indoor UV tanning industry: a review of skin cancer risk, health benefit claims, and regulation. Retrieved from https://www.ncbi.nlm.nih.gov/pubmed/16310065.

37. Moehrle, M., Soballa, M. and Korn, M. (2003), UV exposure in cars. Photodermatology, Photoimmunology \& Photomedicine, 19: 175181. doi:10.1034/j.1600-0781.2003.00031.x

38. Wachler, B. S. B. (2016, July 1). Levels of UV-A Light Protection in Automobile Windshields and Side Windows. Retrieved from https://jamanetwork.com/journals/jamaophthalmol ogy/fullarticle/2522190.

39. Paulson, K. G., lyer, J. G., \& Nghiem, P. (2011, July). Asymmetric lateral distribution of melanoma and Merkel cell carcinoma in the United States. Retrieved from https://www.ncbi.nlm.nih.gov/pmc/articles/PMC31 $17975 /$.

40. Butler, S. T., \& Fosko, S. W. (2010). Increased prevalence of left-sided skin cancers. Journal of the American Academy of Dermatology, 63(6), 1006-1010. doi: 10.1016/j.jaad.2009.11.032

41. Goldstein, A. M., \& Tucker, M. A. (2013, April). Dysplastic nevi and melanoma. Retrieved from https://www.ncbi.nlm.nih.gov/pmc/articles/PMC36 16416/.

42. Palamaras. (2013). Atypical mole. SpringerReference. doi: 10.1007/springerreference_40348 panel, A. links open overlay, \& Publisher Summary This chapter discusses the characteristics. (2008, December 17). Principles of Nonionizing Radiation. Retrieved from https://www.sciencedirect.com/science/article/pii/ B9780815511755500455.

43. Schärer, O. D. (2013, October 1). Nucleotide excision repair in eukaryotes. Retrieved from https://www.ncbi.nlm.nih.gov/pmc/articles/PMC37 83044/.

44. McMeniman, E. K., Duffy, D. L., Jagirdar, K., Lee, K. J., Peach, E., Mclnerney-Leo, A. M., ... Sturm, R. A. (2019, December 3). The interplay of sundamage and genetic risk in Australian multiple and single primary melanoma cases and controls. Retrieved from https://www.ncbi.nlm.nih.gov/pubmed/31794051.

May 2020 Volume 4 Issue 3 
45. Ching, J. A., \& Gould, L. (2012). Giant scalp melanoma: a case report and review of the literature. Eplasty, 12, e51.

46. Anna, B., Blazej, Z., Jacqueline, G., Andrew, C. J., Jeffrey, R., \& Andrzej, S. (2007). Mechanism of UV-related carcinogenesis and its contribution to nevi/melanoma. Retrieved from https://www.ncbi.nlm.nih.gov/pmc/articles/PMC25 $64815 /$.

47. Bray, H. N., Simpson, M. C., Zahirsha, Z. S., Brinkmeier, J. V., Walen, S. G., Fosko, S. W., \& Osazuwa-Peters, N. (Accepted/In press). Head and Neck Melanoma Incidence Trends in the Pediatric, Adolescent, and Young Adult Population of the United States and Canada, 1995-2014. JAMA Otolaryngology - Head and Neck https://doi.org/10.1001/jamaoto.2019.2769

48. Gordon, D., Hansson, J., Eloranta, S., Gordon, M., Gillgren, P., \& Smedby, K. E. (2017, July 12). Primary tumor sites in relation to ultraviolet radiation exposure and skin visibility correlate with survival in cutaneous melanoma. Retrieved from

https://onlinelibrary.wiley.com/doi/10.1002/ijc.308 43.

49. Kirkpatrick, C. S., White, E., \& Lee, J. A. (1994). Case-Control Study of Malignant Melanoma in Washington State. American Journal of Epidemiology, 139(9), 869-880. doi: 10.1093/oxfordjournals.aje.a117093

50. Silva, J. H., Sá, B. C. de, Avila, A. L. R. de, Landman, G., \& Duprat Neto, J. P. (2011). Atypical mole syndrome and dysplastic nevi: identification of populations at risk for developing melanoma - review article. Retrieved from

51. Friedman, R. J., Farber, M. J., Warycha, M. A., Papathasis, N., Miller, M. K., \& Heilman, E. R. (2009). The "dysplastic" nevus. Retrieved from https://www.ncbi.nlm.nih.gov/pubmed/19095156.

52. Weinstock, M. A., Stryker, W. S., Stampfer, M. J., Lew, R. A., Willett, W. C., \& Sober, A. J. (1991, March 15). Sunlight and dysplastic nevus risk. Results of a clinic-based case-control study. Retrieved from https://www.ncbi.nlm.nih.gov/pubmed/2001561.

53. Ellerbroek WC. Oral Contraceptives and Malignant Melanoma. JAMA. 1968;206(3):649650. doi:10.1001/jama.1968.03150030105038

54. Beral, V., Ramcharan, S., \& Faris, R. (1977, December). Malignant melanoma and oral contraceptive use among women in California. Retrieved from https://www.ncbi.nlm.nih.gov/pmc/articles/PMC20 25573/?page $=4$.
55. National Program of Cancer Registries (NPCR). (2019, March 4). Retrieved from https://www.cdc.gov/cancer/npcr/index.htm

56. Roh, M. R., Eliades, P., Gupta, S., Grant-Kels, J. M., \& Tsao, H. (2017). Cutaneous melanoma in women. International journal of women's dermatology, $3(1 \quad$ Suppl), S11-S15. https://doi.org/10.1016/j.jiwd.2017.02.003

57. Hannaford, P. C., Villard-Mackintosh, L., Vessey, M. P., \& Kay, C. R. (1991, March). Oral contraceptives and malignant melanoma. Retrieved from https://www.ncbi.nlm.nih.gov/pmc/articles/PMC19 $71847 /$ ?page $=1$.

58. Holly, E. A., Cress, R. D., \& Ahn, D. K. (1995, May 15). Cutaneous melanoma in women. III. Reproductive factors and oral contraceptive use. Retrieved from https://www.ncbi.nlm.nih.gov/pubmed/7741124.

59. Gandini, S., lodice, S., Koomen, E., Di Pietro, A., Sera, F., \& Caini, S. (2011, November). Hormonal and reproductive factors in relation to melanoma in women: current review and metaanalysis. Retrieved from https://www.ncbi.nlm.nih.gov/pubmed/21620689/.

60. Westerdahl, J., Olsson, H., Måsbäck, A., Ingvar, C., \& Jonsson, N. (n.d.). Risk of malignant melanoma in relation to drug intake, alcohol, smoking and hormonal factors. Retrieved from https://www.nature.com/articles/bjc1996216.

61. Cervenka, I., Mahamat-Saleh, Y., Savoye, I., Dartois, L., Boutron-Ruault, M. C., Fournier, A., \& Kvaskoff, M. (2018, September 13). Oral contraceptive use and cutaneous melanoma risk: a French prospective cohort study. Retrieved from

https://onlinelibrary.wiley.com/doi/abs/10.1002/ijc. 31644.

62. Cervenka, I., Al Rahmoun, M., Mahamat-Saleh, Y., Savoye, I., Boutron-Ruault, M., Fournier, A. and Kvaskoff, M. (2019), Postmenopausal hormone use and cutaneous melanoma risk: $A$ French prospective cohort study. Int. J. Cancer, 145: 1754-1767. doi:10.1002/ijc.32150

63. Koomen, R., E., \& Joosse. (2008, August 25). Estrogens, oral contraceptives and hormonal replacement therapy increase the incidence of cutaneous melanoma: a population-based casecontrol study. Retrieved from https://academic.oup.com/annonc/article/20/2/35 8/164847.

64. Leslie, K. K., \& Espey, E. (2005). Oral contraceptives and skin cancer: is there a link? Retrieved from https://www.ncbi.nlm.nih.gov/pubmed/16343023. 
65. Lê, M. G., Cabanes, P. A., Desvignes, V., Chanteau, M. F., Mlika, N., \& Avril, M. F. (n.d.). Oral contraceptive use and risk of cutaneous malignant melanoma in a case-control study of French women. Retrieved from https://link.springer.com/article/10.1007/BF00124 252.

66. Feskanich, D., Hunter, D. J., Willett, W. C., Spiegelman, D., Stampfer, M. J., Speizer, F. E., \& Colditz, G. A. (1999, November). Oral contraceptive use and risk of melanoma in premenopausal women. Retrieved from https://www.ncbi.nlm.nih.gov/pubmed/10555769.

67. Li, Z., Gu, M., \& Cen, Y. (2014, December 15). Age at first birth and melanoma risk: a metaanalysis. Retrieved from https://www.ncbi.nlm.nih.gov/pmc/articles/PMC43 07469/.

68. Botteri, E., Støer, N. C., Sakshaug, S., GraffIversen, S., Vangen, S., Hofvind, S., ... Weiderpass, E. (2017, July 19). Menopausal hormone therapy and risk of melanoma: Do estrogens and progestins have a different role? Retrieved

from https://onlinelibrary.wiley.com/doi/full/10.1002/ijc. 30878.

69. Wiedemann, C., Nägele, U., Schramm, G., \& Berking, C. (2009, September). Inhibitory effects of progestogens on the estrogen stimulation of melanocytes in vitro. Retrieved from https://www.ncbi.nlm.nih.gov/pubmed/19698824? dopt $=$ Abstract.

70. Ramaraj, P., \& Cox, J. L. (2014, November 15). In vitro effect of progesterone on human melanoma (BLM) cell growth. Retrieved from https://www.ncbi.nlm.nih.gov/pubmed/25550902? dopt=Abstract.

71. Tang, J. Y., Spaunhurst, K. M., Chlebowski, R. T., Wactawski-Wende, J., Keiser, E., Thomas, F., ... Stefanick, M. L. (2011, October 5). Menopausal hormone therapy and risks of melanoma and nonmelanoma skin cancers: women's health initiative randomized trials. Retrieved from https://www.ncbi.nlm.nih.gov/pmc/articles/PMC31 86783/.

72. Snell, R. S., \& Bischitz, P. G. (2016, January 7). The Effect of Large Doses of Estrogen and Estrogen and Progesterone on Melanin Pigmentation. Retrieved from https://www.sciencedirect.com/science/article/pii/ S0022202X15494308.

73. Plasmeijer, Elsemieke I. et al. (March 2017) The Natural History of Common Melanocytic Nevi: A Systematic Review of Longitudinal Studies in the
General Population Journal of Investigative Dermatology, Volume 137, Issue 9, 2017 - 2018

74. Lieberman, R., \& Moy, L. (2008, May). Estrogen receptor expression in melasma: results from facial skin of affected patients. Retrieved from https://www.ncbi.nlm.nih.gov/pubmed/18505139.

75. Johansson, A. L. V., Andersson, T. M.-L., Plym, A., Ullenhag, G. J., Møller, H., \& Lambe, M. (2014, December). Mortality in women with pregnancy-associated malignant melanoma. Retrieved from https://www.ncbi.nlm.nih.gov/pubmed/25440438.

76. Smith, M. A., Fine, J. A., Barnhill, R. L., \& Berwick, M. (1998, October). Hormonal and reproductive influences and risk of melanoma in women. Retrieved from https://www.ncbi.nlm.nih.gov/pubmed/9839729.

77. Zanetti, Roberto, Franceschi, Rosso, Ettore, Colonna, \& Stefano. (1990, September 1). Cutaneous Malignant Melanoma in Females: The Role of Hormonal and Reproductive Factors. Retrieved from https://academic.oup.com/ije/articleabstract/19/3/522/760483

78. Rockley, P. F., Trieff, N., Wagner, R. F., \& Tyring, S. K. (1994). Nonsunlight Risk Factors For Malignant Melanoma Part I: Chemical Agents, Physical Conditions, And Occupation. International Journal of Dermatology, 33(6), 398406. doi: 10.1111/j.1365-4362.1994.tb04038.x

79. De Giorgi, V., Gori, A., Grazzini, M., Rossari, S., Scarfi, F., Corciova, S., ... Massi, D. (2011, May). Estrogens, estrogen receptors and melanoma. Retrieved from https://www.ncbi.nlm.nih.gov/pubmed/21554049? dopt=Abstract.

80. Janik, M. E., Bełkot, K., \& Przybyło, M. (2014). Review is oestrogen an important player in melanoma progression? Współczesna Onkologia, 5, 302-306. doi: 10.5114/wo.2014.43938

81. Marzagalli, M., Montagnani Marelli, M., Casati, L., Fontana, F., Moretti, R. M., \& Limonta, P. (2016, October 26). Estrogen Receptor $\beta$ in Melanoma: From Molecular Insights to Potential Clinical Utility. Retrieved from https://www.ncbi.nlm.nih.gov/pmc/articles/PMC50 80294/.

82. Rivera, A., Nan, H., Li, T., Qureshi, A., \& Cho, E. (2016, December). Alcohol Intake and Risk of Incident Melanoma: A Pooled Analysis of Three Prospective Studies in the United States. Retrieved from https://www.ncbi.nlm.nih.gov/pmc/articles/PMC51 $37801 /$. 
83. Yen, H., Dhana, A., Okhovat, J.-P., Qureshi, A., Keum, N., \& Cho, E. (2017, September). Alcohol intake and risk of nonmelanoma skin cancer: a systematic review and dose-response metaanalysis. Retrieved from https://www.ncbi.nlm.nih.gov/pubmed/28745396.

84. Millen, A. E., Tucker, M. A., Hartge, P., Halpern, A., Elder, D. E., Holly, E. A., ... DuPont Guerry. (2004, June 1). Diet and Melanoma in a CaseControl Study. Retrieved from https://cebp.aacrjournals.org/content/13/6/1042\#r ef-44.

85. Williams, R. R., Stegens, N. L., \& Goldsmith, J. R. (1977). Associations of Cancer Site and Type With Occupation and Industry From the Third National Cancer Survey Interview. JNCl: Journal of the National Cancer Institute, 59(4), 11471185. doi: $10.1093 /$ jnci/59.4.1147

86. Holman CD, Armstrong BK, Heenan PJ. Relationship of cutaneous malignant melanoma to individual sunlight-exposure habits. J Natl Cancer Inst 1986 Mar;76(3):403-14 Abstract available

http://www.ncbi.nlm.nih.gov/pubmed/3456458

87. Stryker, W. S., Stampfer, M. J., Stein, E. A., Kaplan, L., Louis, T. A., Sober, A., \& Willett, W. C. (1990). Diet, Plasma Levels Of Beta-Carotene And Alpha-Tocopherol, And Risk Of Malignant Melanoma. American Journal of Epidemiology, 131(4), 597-611. doi: 10.1093/oxfordjournals.aje.a115544

88. Veierød, M. B., Thelle, D. S., \& Laake, P. (1997, May 16). Diet and risk of cutaneous malignant melanoma: a prospective study of 50,757 Norwegian men and women. Retrieved from https://www.ncbi.nlm.nih.gov/pubmed/9178814?d opt=Abstract.

89. Osterlind, A., Tucker, M. A., Stone, B. J., \& Jensen, O. M. (1988, December 15). The Danish case-control study of cutaneous malignant melanoma. IV. No association with nutritional factors, alcohol, smoking or hair dyes. Retrieved from

https://www.ncbi.nlm.nih.gov/pubmed/3192325?d opt=Abstract.

90. Seitz, H. K., \& Mueller, S. (2015). Alcohol and cancer: an overview with special emphasis on the role of acetaldehyde and cytochrome P450 2E1. Retrieved

from https://www.ncbi.nlm.nih.gov/pubmed/25427901/.

91. Brooks, P. J., \& Theruvathu, J. A. (2005, April). DNA adducts from acetaldehyde: implications for alcohol-related carcinogenesis. Retrieved from https://www.ncbi.nlm.nih.gov/pubmed/16054980.

92. De Pergola, G., \& Silvestris, F. (2013). Obesity as a major risk factor for cancer. Retrieved from
https://www.ncbi.nlm.nih.gov/pmc/articles/PMC37 73450/.

93. Sergentanis, T. N., Antoniadis, A. G., Gogas, H. J., Antonopoulos, C. N., Adami, H.-O., Ekbom, A., \& Petridou, E. T. (2013). Obesity and risk of malignant melanoma: A meta-analysis of cohort and case-control studies. European Journal of Cancer, 49(3), 642-657. doi: 10.1016/j.ejca.2012.08.028

94. Greenlee, H., Unger, J. M., Leblanc, M., Ramsey, S., \& Hershman, D. L. (2016). Association between Body Mass Index and Cancer Survival in a Pooled Analysis of 22 Clinical Trials. Cancer Epidemiology Biomarkers \& Prevention, 26(1), 21-29. doi: 10.1158/1055-9965.epi-15-1336

95. Schneider, G., Kirschner, M. A., Berkowitz, R., \& Ertel, N. H. (1979, April). Increased estrogen production in obese men. Retrieved from https://www.ncbi.nlm.nih.gov/pubmed/429508.

96. Jacob, L., Freyn, M., Kalder, M., Dinas, K., \& Kostev, K. (2018). Impact of tobacco smoking on the risk of developing 25 different cancers in the UK: a retrospective study of 422,010 patients followed for up to 30 years. Oncotarget, 9(25), 17420-17429. doi:10.18632/oncotarget.24724

97. Kessides, M. C., Wheless, L., Hoffman-Bolton, J., Clipp, S., Alani, R. M., \& Alberg, A. J. (2011, January). Cigarette smoking and malignant melanoma: a case-control study. Retrieved from https://www.ncbi.nlm.nih.gov/pmc/articles/PMC29 24442/.

98. Freedman, D. M., Sigurdson, A., Doody, M. M., Rao, R. S., \& Linet, M. S. (n.d.). Risk of melanoma in relation to smoking, alcohol intake, and other factors in a large occupational cohort. Retrieved from https://link.springer.com/article/10.1023/B:CACO. 0000003839.56954.73.

99. Shaw, H. M., \& Milton, G. W. (2006, July 17). Smoking and the development of metastases from malignant melanoma. Retrieved from https://onlinelibrary.wiley.com/doi/pdf/10.1002/ijc. 2910280207.

100. Dusingize, J. C., Olsen, C. M., Pandeya, N., Thompson, B. S., Webb, P. M., Green, A. C., ... Whiteman, D. C. (2018, January 1). Smoking and cutaneous melanoma: findings from The QSkin Sun and Health cohort study. Retrieved from https://cebp.aacrjournals.org/content/early/2018/0 5/22/1055-9965.EPI-17-1056.

101. Ombra1, M. N., Paliogiannis, P., Colombino, M., Casula, M., Sini, M. C., Manca, A., ... Queirolo, P. (2019, May 21). Dietary compounds and cutaneous malignant melanoma: recent advances from a biological perspective. Retrieved from May 2020 Volume 4 Issue 3 
https://nutritionandmetabolism.biomedcentral.co m/articles/10.1186/s12986-019-0365-4.

102. Wu, H., Reeves, K. W., Qian, J., \& Sturgeon, S. R. (1970, January 1). Coffee, tea, and melanoma risk among postmenopausal women.: Semantic Scholar. Retrieved from https://www.semanticscholar.org/paper/Coffee,-tea,-and-melanoma-risk-among-postmenopausalWu-

Reeves/78cbe763db2650824dd9d15b0de7e072 bd7e553f.

103. Kang, S. J., Choi, B. R., Lee, E. K., Kim, S. H., Yi, H. Y., Park, H. R., ... Ku, S. K. (2015, October 13). Inhibitory Effect of Dried Pomegranate Concentration Powder on Melanogenesis in B16F10 Melanoma Cells; Involvement of p38 and PKA Signaling Pathways. Retrieved from https://www.ncbi.nlm.nih.gov/pubmed/26473849? dopt=Abstract.

104. Wu, Y., Jia, L.-L., Zheng, Y.-N., Xu, X.-G., Luo, Y.-J., Wang, B., ... Li, Y.-H. (2013, March). Resveratrate protects human skin from damage due to repetitive ultraviolet irradiation. Retrieved from

https://www.ncbi.nlm.nih.gov/pubmed/22221158? dopt=Abstract.

105. Anstey, A. V. (2002, May). Systemic photoprotection with alpha-tocopherol (vitamin E) and beta-carotene. Retrieved from https://www.ncbi.nlm.nih.gov/pubmed/12072001? dopt=Abstract.

106. Baccarin, T., Mitjans, M., Lemos-Senna, E., \& Vinardell, M. P. (2015, December 25). Protection against oxidative damage in human erythrocytes and preliminary photosafety assessment of Punica granatum seed oil nanoemulsions entrapping polyphenol-rich ethyl acetate fraction. Retrieved from https://www.ncbi.nlm.nih.gov/pubmed/26407526? dopt=Abstract.

107. Timerman, D., McEnery-Stonelake, M., Joyce, C. J., Nambudiri, V. E., Hodi, F. S., Claus, E. B., ... Lin, J. Y. (2017, January 24). Vitamin D deficiency is associated with a worse prognosis in metastatic melanoma. Retrieved from https://www.ncbi.nlm.nih.gov/pmc/articles/PMC53 51676/.

108. Russo, I., Caroppo, F., \& Alaibac, M. (2015, July 24). Vitamins and Melanoma. Retrieved from https://www.ncbi.nlm.nih.gov/pmc/articles/PMC45 86774/.

109. Yew, Y. W., Lai, Y. C., \& Schwartz, R. A. (2015, November 7). Coffee Consumption and Melanoma: A Systematic Review and MetaAnalysis of Observational Studies. Retrieved from

https://link.springer.com/article/10.1007/s40257015-0165-1.

110. Wang, J., Li, X., \& Zhang, D. (2016, June). Coffee consumption and the risk of cutaneous melanoma: a meta-analysis. Retrieved from https://www.ncbi.nlm.nih.gov/pubmed/26695410? dopt=Abstract.

111. Wu, S., Han, J., Song, F., Cho, E., Gao, X., Hunter, D. J., \& Qureshi, A. A. (2015, November). Caffeine Intake, Coffee Consumption, and Risk of Cutaneous Malignant Melanoma. Retrieved from https://www.ncbi.nlm.nih.gov/pubmed/26172864? dopt=Abstract.

112. Asgari, M. M., Brasky, T. M., \& White, E. (2015, December 8). Association of Vitamin A and Carotenoid Intake with Melanoma Risk in a Large Prospective Cohort. Retrieved from https://www.sciencedirect.com/science/article/pii/ S0022202X15357924.

113. Setlow, R. B., Grist, E., Thompson, K., \& Woodhead, A. D. (1993). Wavelengths effective in induction of malignant melanoma. Proceedings of the National Academy of Sciences, 90(14), 6666-6670. doi: 10.1073/pnas.90.14.6666

114. Austin, D. F., \& Reynolds, P. (1997). Investigation of an Excess of Melanoma among Employees of the Lawrence Livermore National Laboratory. American Journal of Epidemiology, 145(6), 524-531. doi: 10.1093/oxfordjournals.aje.a009140

115. Fink, C. A., \& Bates, M. N. (2005). Melanoma and lonizing Radiation: Is There a Causal Relationship? Radiation Research, 164(5), 701710. doi: $10.1667 / \mathrm{rr} 3447.1$

116. Freedman, D. M., Sigurdson, A., Doody, M. M., Rao, R. S., \& Linet, M. S. (n.d.). Risk of melanoma in relation to smoking, alcohol intake, and other factors in a large occupational cohort. Retrieved from https://link.springer.com/article/10.1023/B:CACO. 0000003839.56954.73.

117. Azizova, T. V., Bannikova, M. V., Grigoryeva, E. S., \& Rybkina, V. L. (2018). Risk of malignant skin neoplasms in a cohort of workers occupationally exposed to ionizing radiation at low dose rates. Plos One, 13(10). doi: 10.1371/journal.pone.0205060

118. Larsson, B. S. (1993). Interaction Between Chemicals and Melanin. Pigment Cell Research, $6(3)$, 127-133. doi: 10.1111/j.16000749.1993.tb00591.x

119. Neagu, M., Caruntu, C., Constantin, C., Boda, D., Zurac, S., Spandidos, D. A., \& Tsatsakis, A. M. (2016, May). Chemically induced skin carcinogenesis: Updates in experimental May 2020 Volume 4 Issue 3 
models (Review). Retrieved from https://www.ncbi.nlm.nih.gov/pmc/articles/PMC48 $11393 /$

120. Baudouin, C., Charveron, M., Tarroux, R., \& Gall, Y. (n.d.). Environmental pollutants and skin cancer. Retrieved from https://link.springer.com/article/10.1023/A:101954 0316060.

121. Mehlman, M. A. (2006). Causal Relationship from Exposure to Chemicals in Oil Refining and Chemical Industries and Malignant Melanoma. Annals of the New York Academy of Sciences, 1076(1), 822-828. doi: 10.1196/annals.1371.005

122. Jalilian, H., Ziaei, M., Weiderpass, E., Rueegg, C. S., Khosravi, Y., \& Kjaerheim, K. (2019). Cancer incidence and mortality among firefighters. International Journal of Cancer, 145(10), 2639-2646. doi: 10.1002/ijc.32199

123. Gallagher, R. P., Lee, T. K., Weber, J.-P., Leblanc, A., Borugian, M., Elwood, J. M., ... Spinelli, J. J. (2010, September 24). Polychlorinated biphenyls (PCB), UV radiation, and cutaneous malignant melanoma. Retrieved from

https://www.ncbi.nlm.nih.gov/pmc/articles/PMC32 54998/.

124. Bahn, A. K., Rosenwaike, I., Hermann, N., Grover, P., Stellman, J., \& O'Leary, K. (1976, August 19). Letter: Melanoma after exposure to PCB's. Retrieved from https://www.ncbi.nlm.nih.gov/pubmed/819831.

125. Brown, D. P., \& Jones, M. (1981). Mortality and Industrial Hygiene Study of Workers Exposed to Polychlorinated Biphenyls. Archives of Environmental Health: An International Journal, 36(3), 120-129. doi: 10.1080/00039896.1981.10667615

126. Zani, C., Ceretti, E., Covolo, L., \& Donato, F. (2017, September). Do polychlorinated biphenyls cause cancer? A systematic review and metaanalysis of epidemiological studies on risk of cutaneous melanoma and non-Hodgkin lymphoma. Retrieved from https://www.ncbi.nlm.nih.gov/pubmed/28535466.

127. Purdue, M. P., Hoppin, J. A., Blair, A., Dosemeci, M., \& Alavanja, M. C. R. (2007, February 1). Occupational exposure to organochlorine insecticides and cancer incidence in the Agricultural Health Study. Retrieved from https://www.ncbi.nlm.nih.gov/pmc/articles/PMC19 71137/.

128. Dennis, L. K., Lynch, C. F., Sandler, D. P., \& Alavanja, M. C. (2010). Pesticide use and cutaneous melanoma in pesticide applicators in the agricultural heath study. Environmental health perspectives, $\quad 118(6)$,

https://doi.org/10.1289/ehp.0901518
812-817. 